\title{
RESPONSABILIDADE AMBIENTAL EMPRESARIAL E SUA DIMENSÃO
}

\author{
TRANSNACIONAL
}

Carla Piffer ${ }^{1}$

Helena Liebl ${ }^{2}$

Recebido em: 05 nov. 2019

Aceito em: 12 nov. 2019

\begin{abstract}
Como citar este artigo: PIFFER, C.; LIEBL, H. RESPONSABILIDADE AMBIENTAL EMPRESARIAL E SUA DIMENSÃO TRANSNACIONAL. Revista Visão: Gestão Organizacional, Caçador, SC, Brasil, p. 101-114, jun./dez. 2019. ISSN 2238-9636. Disponível em:

<https://doi.org/10.33362/visao.v8i2.2150>.
\end{abstract}

Resumo: O presente artigo tem como escopo estudar a Responsabilidade Ambiental Empresarial na sua dimensão transnacional. O mundo se tornou globalizado e com isso o Direito Internacional não é suficiente para atender às demandas da sociedade globalizada, surgindo então o Direito Transnacional, responsável por demonstrar que as fronteiras entre os países estão se desvanecendo e com isso também a soberania nacional em determinados aspectos. Entretanto, com a globalização, os desastres naturais e a devastação do meio ambiente se tornaram crescentes. Assim, se faz necessário que a humanidade se conscientize e se torne responsável socialmente com as questões econômicas, sociais e ambientais. Por tais mudanças ocorridas na sociedade civil global e a relevância de estudos sobre elas, o presente artigo tem como problema central o de descobrir a relação entre a Responsabilidade Ambiental Empresarial e a transnacionalidade. Como objetivos específicos pretende-se: discorrer sobre a Responsabilidade Ambiental Empresarial; analisar as principais características da transnacionalidade; e investigar sobre a Responsabilidade Ambiental Empresarial no seu aspecto transnacional. Ao final, são tecidos comentários referente à necessidade de prosseguir investigações sobre o assunto, visto que os desastres naturais causados por empresas atingem a toda uma população, transpondo as fronteiras dos Estados nacionais. Necessita-se, portanto, da conscientização por parte também das empresas, no sentido de que suas ações devem ser ambientalmente responsáveis, a fim de conceber um bem maior para a coletividade global. Quanto à Metodologia, utiliza-se o Método Indutivo, sendo acionadas as técnicas do Referente, da Categoria, do Conceito Operacional e da Pesquisa Bibliográfica.

Palavras-Chave: Responsabilidade Ambiental Empresarial. Transnacionalidade. Direito

\footnotetext{
1 Pós-Doutora em Direito pela Universidade de Passo Fundo - UPF. Mestre e Doutora em Ciência Jurídica pela Universidade do Vale do Itajaí - UNIVALI. Doutora em Diritto Pubblico pela Università degli Studi di Perugia, Itália. Professora do Programa de Pós-Graduação Stricto Sensu - Mestrado e Doutorado - em Ciência Jurídica da Universidade do Vale do Itajaí - UNIVALI. E-mail: cpiffer79@hotmail.com.

2 Advogada. Mestranda em Ciência Jurídica pela UNIVALI com dupla titulação com a Universidade de Alicante/Espanha. Membro imortal da Academia de Letras do Brasil de Santa Catarina Seccional Balneário Piçarras/SC. Sócia-advogada no escritório Duarte e Liebl Advogados Associados. Escritora. E-mail: helenali.liebl@gmail.com.
} 
Ambiental.

\section{BUSINESS ENVIRONMENTAL RESPONSIBILITY AND ITS TRANSNATIONAL DIMENSION}

Abstract: The purpose of this article is to study business environmental responsibility in its transnational dimension. The world has become globalized and, as a result, international law is not sufficient to meet the demands of globalized society, and then transnational law has emerged, which is responsible for demonstrating that the borders between countries are fading, and thus national sovereignty in certain respects. However, with globalization, natural disasters and environmental devastation have become increasingly. Thus, it is necessary for humanity to become aware and socially responsible with economic, social and environmental issues. Due to such changes in global civil society and the relevance of studies on them, this article has as its central problem that of discovering the relationship between Corporate Environmental Responsibility and transnationality. The specific objectives are: to discuss Corporate Environmental Responsibility; analyze the main characteristics of transnationality; and investigate Corporate Environmental Responsibility in its transnational aspect. At the end, comments are made on the need to pursue further investigations on the subject, as natural disasters caused by businesses hit a whole population across national borders. Therefore, companies also need to be aware that their actions must be environmentally responsible in order to conceive a greater good for the global community. As for the Methodology, the Inductive Method is used, using the techniques of the Referent, Category, Operational Concept and Bibliographic Research.

Keywords: Business environmental responsibility. Transnationality. Environmental law.

\section{INTRODUÇÃO}

Com o passar dos anos, percebeu-se que os Estados nacionais estão vivenciando a fragilização das suas fronteiras, sob vários aspectos, pois os problemas que antes eram locais, estão se tornando globais, principalmente na questão ambiental.

A Responsabilidade Ambiental Empresarial ganhou visibilidade nos últimos anos em decorrência dos avanços da degradação ambiental e dos recursos naturais em geral, em virtude dos avanços tecnológicos e industriais.

O conceito de empresa também vem se modificando, compreendendo que a atividade econômica deve também se orientar de acordo com o significado que esta possui na sociedade, sendo, portanto, um sistema social, possuindo considerável responsabilidade social, concretizando o respeito pelos direitos humanos, melhoria na qualidade de vida e preservação do meio ambiente natural.

Assim, o presente artigo tem como problema central evidenciar a relação entre a Responsabilidade Ambiental Empresarial e a transnacionalidade.

E como objetivos específicos pretende-se: discorrer sobre a Responsabilidade Ambiental Empresarial; analisar as principais características da transnacionalidade; e investigar 
sobre a Responsabilidade Ambiental Empresarial no seu aspecto transnacional.

Quanto à Metodologia (Pasold, 2015, p. 27 e 39), aponta-se que foi utilizado o Método Indutivo, sendo acionadas as técnicas do Referente, da Categoria, do Conceito Operacional e da Pesquisa Bibliográfica.

\section{DA RESPONSABILIDADE AMBIENTAL EMPRESARIAL}

Há diferentes perspectivas acerca da Responsabilidade Social, no sentido de se poder representar a ideia de responsabilidade coletiva, imposição normativa legal ou comportamento coletivo responsável e ético.

Conforme Mascarenhas (2011, p. 143), a Responsabilidade Social e Ambiental se refere "à ética como procedimento condutor das ações com todos os públicos com os quais a organização pode interagir, ou seja, os seus stakeholders sociais".

Para o ISSO 26000 (2010, p. 04), a Responsabilidade Social é definida como a "responsabilidade de uma organização pelos impactos de suas decisões e atividades na sociedade e no meio ambiente, por meio de um comportamento ético e transparente".

Assim, ao orientar-se de acordo com a Responsabilidade Social, a empresa estará contribuindo, além do desenvolvimento sustentável, também para com a sociedade onde está inserida, com o meio ambiente, enfim, contribuindo para uma melhoria contínua social e ambiental. Quanto a isso:

Estratégia de responsabilidade socioambiental não significa apenas que a empresa tenha uma ligação direta com a sociedade e o meio ambiente, significa que, além de envolver todas essas questões, a organização está interligada através de seus processos, atitudes, coerência e boas práticas que a mesma realiza para o bem estar da coletividade (LACERDA, 2016, p. 12).

Destarte, há que se ressaltar que houve certa alteração na percepção das corporações sobre o seu papel na sociedade, sendo vista também com um papel relevante no acompanhamento e participação de tarefas sociais, e não apenas com propósitos econômicos (PALHARES, 2010).

A Cúpula Mundial de Desenvolvimento Sustentável (Rio + 10), ocorrida em 2002 em Johanesburgo, definiu o conceito de Responsabilidade Social Empresarial como "o compromisso da empresa de contribuir ao desenvolvimento econômico sustentável, trabalhando com os empregados, suas famílias, a comunidade local e a sociedade em geral para melhorar sua qualidade de vida" (DIAS, 2007, p. 154).

Para Dias (2007, p.153), a Responsabilidade Social Empresarial vai muito além de cumprir as legislações ambientais e sociais, pois "promove um comportamento empresarial [...] que atendem às expectativas da sociedade em relação à empresa". 
Outrossim, o conceito de Responsabilidade Social Ambiental pressupõe a construção social de um conceito amplo, que abrange os conceitos de cidadania corporativa, desenvolvimento sustentável, crescimento sustentável, sustentabilidade, filantropia empresarial, ética empresarial e ativismo social empresarial (MASCARENHAS, 2011).

Deste modo, a Responsabilidade Ambiental Empresarial, ramo da Responsabilidade Social Ambiental, tem como um dos seus pressupostos a cooperação e interação com a comunidade sobre questões sociais e ambientais e suas necessidades e expectativas, a qual leva em consideração os valores e atingir com o intuito de atingir os seus objetivos. Assim, "a responsabilidade social e ambiental desencadeia processos de socialização ecológica e ética, de solidariedade social e ambiental" (MASCARENHAS, 2011, p. 146).

Quanto a esta integração das empresas, menciona Mascarenhas (2011, p.148):

[...] trata-se de uma integração voluntária de preocupações sociais e ambientais por parte das empresas nas suas operações e na sua interação com outras partes interessadas (Livro Verde da Comissão Europeia, 2001). Ainda que o objetivo primeiro das empresas seja a obtenção de rentabilidade económica, pretende-se que a possam atingir a favor da sociedade, isto é, que possam contribuir, simultaneamente, para o cumprimento dos objetivos sociais e ambientais, mediante a integração destes na sua estratégia. Nesta ótica, «há uma preocupação com as interações desenvolvidas entre as empresas e a sociedade, assumindo aquelas a sua «razão de ser» de uma forma mais abrangente intimamente associada à sociedade envolvente e ao impacto que nela provoca.

A Responsabilidade Social Ambiental, então, está assentada em três paradigmas que exigem mudanças nas empresas, quais seja: econômico, ambiental e social.

Devido ao objetivo central deste estudo, o foco de análise cinge-se ao paradigma ambiental da Responsabilidade Social Empresarial, ante às constantes mudanças vivenciadas pelas empresas, as quais necessitam de eficientes estratégias empresariais quanto às preocupações ambientais, implementação dos sistemas de gestão ambiental, certificações, e atuação sobre os impactos ambientais das suas atividades.

Assim, a Responsabilidade Ambiental Empresarial se torna uma estratégia de negócios com impactos positivos em sua imagem corporativa, fortalecendo a sua dimensão econômica e faz com que as organizações tendam a obter vantagens, conforme explana o ISSO ABNT NRB 26000:2010 (2010, p.07):

A percepção e a realidade do desempenho em responsabilidade social da organização podem influenciar, além de outros, os seguintes fatores: sua vantagem competitiva, sua reputação, sua capacidade de atrair e manter trabalhadores e/ou conselheiros, sócios e acionistas, clientes ou usuários, a manutenção de investidores, proprietários, doadores, patrocinadores, e da comunidade financeira e sua relação com empresas, governos, mídia, fornecedores, organizações pares, clientes e a comunidade em que opera.

Não obstante, a Responsabilidade Ambiental Empresarial, em sendo também social, 
resgata a função social da empresa quanto à promoção da qualidade do ambiento do trabalho, respeitando as pessoas, a comunidade e o meio ambiente. Nesse sentido:

\begin{abstract}
A Responsabilidade Socioambiental entra como estratégia numa organização, gerando vantagem competitiva capaz de produzir valores e consequentemente benefícios para a empresa como, agregação de valor à imagem e preferência no momento de escolha pelos clientes (LACERDA, 2016, p.03).
\end{abstract}

Destarte, as empresas adquiriram certa consciência ecológica em decorrência da pressão do Poder Público, da opinião pública, dos consumidores, bem como pela melhoria na sua imagem em virtude de tal responsabilidade, resultando em aumento dos seus benefícios:

De qualquer modo, como resultado dessa preocupação ambiental, associada com as exigências legais e éticas da sociedade, muitas empresas têm procurado gradativamente assumir maior responsabilidade ecológica, adotando um papel mais ativo (DIAS, 2007, p.156).

Dentre as possíveis ações para a implementação de uma gestão ambiental responsável, de acordo com Dias (2007, p. 156), estão:

- Implantar um sistema de gestão ambiental;

- Proceder a modificações no processo produtivo, substituindo os produtos tóxicos ou nocivos por outros menos prejudiciais;

- $[\ldots]$

- Elaborar códigos de conduta de respeito ao meio ambiente;

- $[\ldots]$

- Diminuir o consumo de matérias-primas, água e energia;

Outrossim, de acordo com a Confederação Nacional da Indústria, as empresas necessitam ter como princípios básicos para o desenvolvimento sustentável e a responsabilidade social o reconhecimento de que a educação, erradicação da pobreza, entre outras questões, são fundamentais e que é responsabilidade da empresa utilizar de forma sustentável seus recursos naturais, junto com o governo e a sociedade (DIAS, 2007, p.157).

Com isso, fica evidente o tripé da sustentabilidade, que envolve os aspectos sociais, econômicos e ambientais (LACERDA, 2016, p.03), os três com igual relevância e se completando um ao outro.

Todavia, não há um consenso universal quanto à definição da Responsabilidade Social e Ambiental das empresas, por mais que se saiba que ela surge de uma atitude ética das mesmas perante a sociedade em que está inserida e sua relação com o meio ambiente.

Entretanto, sabe-se que as atitudes praticadas em um local, podem ter suas consequências sentidas em outros, e por isso, é relevante tratar da Transnacionalidade, ou seja, 
das ocorrências que transpassam as fronteiras físicas estatais, mormente quando se trata de Responsabilidade Social Empresarial.

\section{DA TRANSNACIONALIDADE}

Os modelos de Direito Nacional e Internacional não são mais suficientes para apresentar respostas sobre as atuais demandas à sociedade e às instituições, pois as mudanças oriundas da atual sociedade globalizada trouxeram à tona a existência do Direito Transnacional, que se apresentou como o modelo mais adequado à tais transformações sociais.

Assim, as questões econômicas, sociais, ambientais, entre outras, se tornaram globais.

A expressão Transnacionalidade surgiu com o Philip Jessup (PIFFER; CRUZ, 2018), sendo que, Direito Transnacional, inclui todas as normas que transcendem as fronteiras nacionais, podendo envolver, indivíduos, empresas, Estados, organizações de Estado, entre outros (JESSUP, 1965).

De acordo com Jessup (1965, p.62), a função do Direito Transnacional é "ajustar os casos e distribuir a jurisdição de maneira mais proveitosa para as necessidades e conveniências de todos os membros da comunidade internacional".

Ribeiro (1997) também estudou a Transnacionalidade, defendendo que discutir a sua condição implicaria em levantar a possibilidade de modificações das concepções de cidadania, criando uma responsabilidade com relação às consequências das ações políticas e econômicas no mundo global.

De certa forma, então, o Direito Transnacional pode ser representado por normas globais internalizadas nos Estados Nacionais, bem como normas nacionais internalizadas em outros Estados Nacionais, como sendo, portanto, normas globais (KOH, 2006).

Segundo Koh (2006), o Direito Transnacional tem como uma de suas principais características a integração entre os países, suas normas e políticas.

Com isso, o Direito Transnacional é relevante porque influencia em muito as leis e políticas que governam os Estados nacionais, principalmente quando essas leis e políticas internacionais são internalizadas pelos mesmos.

Bodnar e Cruz (2009, p.04) estabelecem para o Estado e Direito Transnacional as seguintes características:

a) Constituição a partir de estados em processos de abdicação intensa das competências soberanas;

b) Formação por instituições com órgãos e organismos de governança, regulação, intervenção e aplicação das normas transnacionais;

c) Capacidade fiscal em diversos âmbitos transnacionais, como em questões vitais ambientais, financeiras, circulação de bens e serviços, dentre outros não menos importantes;

d) Atuação em âmbitos difusos transnacionais: questão vital ambiental, 
manutenção da paz, direitos humanos, dentre outros;

e) Pluralismo de concepção, para incluir nações que não estão organizadas politicamente a partir da lógica judaico-cristã ocidental;

f) Implantação gradativa de instrumentos de democracia transnacional deliberativa e solidária;

g) Constituição dos espaços públicos transnacionais especialmente com base na cooperação, solidariedade e no consenso;

h) Capacidade de coerção, como característica fundamental, destinada a garantir a imposição dos direitos e deveres estabelecidos democraticamente a partir do consenso, superando assim uma das principais dificuldades de atuação dos estados no plano externo.

Com base nessas características, os autores sugerem o seguinte conceito de Estado Transnacional:

\begin{abstract}
A partir destas reflexões, pode-se sugerir o conceito de Estado Transnacional como sendo a emergência de novos espaços públicos plurais, solidários e cooperativamente democráticos e livres das amarras ideológicas da modernidade, decorrentes da intensificação da complexidade das relações globais, dotados de capacidade jurídica de governança, regulação, intervenção-e coerção-e com o objetivo de projetar a construção de um novo pacto de civilização (CRUZ; BODNAR, 2009, p.06).
\end{abstract}

Para Koh (2006, p.01), o Direito Transnacional é um híbrido entre o direito doméstico e internacional, de demasiada relevância na vida das sociedades contemporâneas:

Pode-se pensar no direito transnacional como um direito que não é puramente doméstico e nem puramente internacional, mas sim, um híbrido dos dois. Considere, por exemplo, o sistema métrico ou o conceito de negócio da internet do "ponto.com". [...]. Ambos são híbridos, ideias puramente transnacionais.

Assim, a transnacionalidade é um fenômeno que emerge da intensificação das relações advindas da globalização (PIFFER; CRUZ, 2017), isto, porque a ela nasce da globalização.

Outrossim, com as alterações incitadas pela globalização, ocasionou novas situações, antes não ocasionadas, vez que não atendem mais a espaços territoriais pré-definidos, motivo pelo qual a transnacionalidade não possui um território circunscrito:

Eis a razão pela qual a transnacionalidade atravessa diferentes níveis de integração tornando difícil relacioná-la a um território circunscrito. Esta é a característica da desterritorialização atribuída à transnacionalidade por Stelzer sob o argumento de que o território transnacional se situa na fronteira transpassada, na borda permeável do Estado 16, flutuando sobre os Estados e fronteiras (PIFFER; CRUZ, 2017, p.125).

Portanto, a Transnacionalidade se manifesta no cotidiano das pessoas e instituições nas mais variadas localidades globais. Destarte, a União Européia é um exemplo dos acontecimentos transnacionais, já que comtempla vários países que se reúnem para tomar as mais diversas decisões (PIFFER, CRUZ, 2017). 
Ribeiro(1997), ao tratar sobre as condições da transnacionalidade - que, segundo o autor, são separáveis -, as individualiza em: condições integrativas, históricas, econômicas, tecnológicas, ideológicas e culturais, sociais e rituais.

A condição integrativa se relaciona com o fato da transnacionalidade fazer parte de famílias que se localizam geográfica e politicamente, tratando, pois, dos níveis de integração entre as diversas pessoas localizadas em diversos países (RIBEIRO, 1997).

A condição histórica aborda o fato do transnacionalismo ser um fato histórico, que segundo o autor, se supõe o entrelaçamento de duas forças, o amadurecimento dos Estadosnações e o exacerbamento do processo de globalização (RIBEIRO, 1997).

Quanto à condição econômica se relaciona ao transnacionalismo porque a economia sempre ultrapassou as fronteiras dos países, por conta também das redes supranacionais de instituições financeiras (RIBEIRO, 1997).

A condição tecnológica é relativa à globalização do tempo, pois as redes globais de telecomunicação possuem função político-econômica ao reder do planeta (RIBEIRO, 1997).

As condições ideológica e cultural trata do debate acerca da integração entre a globalização e a natureza dos fenômenos culturais, apresentando-se hoje, quase que como uma "cultura global" (RIBEIRO, 1997).

Já as condições sociais, abordam a emergência de um novo nível de integração de uma elite que desejam a consolidação de condições institucionais e ideológicas (RIBEIRO, 1997).

Por fim, as condições rituais se relacionam com os rituais dos ricos e poderes cosmopolitas e suas integrações, como por exemplo, os encontros do G7, demonstra um mundo sem fronteiras, em que há um campo de poder, que segundo o autor, os agentes necessitam "ocupar suas posições” (RIBEIRO, 1997).

No mesmo estudo, Ribeiro (1997, p.02) trata de uma particularidade da transnacionalidade que é o "pertencimento a unidades sócio-culturais e político-culturais":

O transnacionalismo tem fronteiras e similaridades com temáticas como globalização, sistema mundial e divisão internacional do trabalho. Mas sua própria particularidade reside no fato da transnacionalidade apontar para uma questão central: a relação entre territórios e os diferentes arranjos sócio-culturais e políticos que orientam as maneiras como as pessoas representam pertencimento a unidades sócio-culturais, políticas e econômicas. Isto é o que denomino modos de representar pertencimento a unidades sócio-culturais e político-econômicas.

Com um Estado Transnacional, a Soberania nacional fica por vezes defasada, pois não há uma soberania única para cada país. Quanto a isso:

Toda vez que prevalece la idea de un organismo internacional sin que haya la hegemonía de una Nación o de un grupo de naciones estamos, y verdaderamente, superando el concepto de Estado Constitucional Moderno, cuyo atributo principal es la Soberanía, que tiene dificultad para convivir con la idea de un sistema transnacional (CRUZ; FERRER, 2008, p.17). 
Cruz e Ferrer (2008) argumentam que nesse sentido o Estado Constitucional Moderno Soberano também não se sustenta, isto porque com uma economia mundial e a globalização, a Soberania perde força e com isso também o Estado Soberano, que se torna interdependente das relações com os outros Estados.

Abordam sobre a possibilidade de que a globalização impulsione novas formas de integração e pressupostos democráticos, "que permitan el comienzo de uma caminada en dirección a una mayor fraternidad universal y un desarrollo común solidário" (CRUZ; FERRER, 2008, p.17).

Feitas estas considerações sobre a Transnacionalidade, parte-se para o estudo da relação desta com a Responsabilidade Ambiental Empresarial, de extrema relevância para este estudo.

\section{DA RESPONSABILIDADE AMBIENTAL EMPRESARIAL E SUA DIMENSÃO TRANSNACIONAL}

O surgimento e consequente crescimento da globalização fez com que surgisse uma nova ordem mundial, influenciada por tal fenômeno que abre precedente para a organização de espaços públicos transnacionais que auxiliem na cooperação e na solidariedade das relações.

Com a globalização sobreveio uma economia internacional (transnacionalidade), que é uma "fonte de desequilíbrios e injustiças [...] que colocaram a humanidade numa inegável crise civilizatória que pode comprometer, inclusive, a sua continuação como espécie" (CRUZ, BODNAR, 2012, p.56).

Além disso, com a globalização os problemas econômicos, socais e, principalmente, ambientais se agravaram. O uso desenfreado dos recursos naturais, a poluição desmedida e o desmatamento, fazem com que inclusive a espécie humana, corra risco de extinção, isto porque se depende em muito do meio ambiente:

Boaventura de Souza Santos indica que a crise ambiental decorre diretamente da transnacionalização da pobreza, da miséria e da fome e o autor inclui a degradação ambiental dentre os principais problemas na relação social mundial" (CRUZ; BODNAR, 2012, p.113).

O Estado precisa garantir para a Sociedade condições dignas de existência atendendo as suas necessidades, o que é fortemente relativo com o desenvolvimento industrial e com a globalização, porém sem agredir o meio ambiente.

O Estado, juntado com a sociedade e instituições, possuem uma função de demasiada relevância, que é a proteção ambiental e a sustentabilidade, porém sem prejudicar o mercado, que move a economia global.

Portanto, o estudo da Responsabilidade Ambiental Empresarial e a sua dimensão 
transnacional é de suma relevância para a análise de como o Direito Transnacional e a Responsabilidade Ambiental podem ser imprescindíveis para o alcance da sustentabilidade e de um desenvolvimento sustentável.

A proteção ambiental deve ser analisada juntamente com a globalização, tendo em vista que os recursos naturais são finitos e de bem comum de todos, não havendo, portanto, fronteiras ou soberania, se relacionando diretamente com a transnacionalidade e a solidariedade:

A solidariedade, conforme já abordado no presente artigo, desperta a necessidade de regular interesses coletivos antes e acima dos interesses individuais e/ou parciais, trazendo a possibilidade se de garantir a sobrevivência das diversas e futuras gerações de todas as nações (NASCIMENTO, 2013, p.506).

A solidariedade quando vinculada à sustentabilidade "quebra o paradigma da individualidade porque o bem jurídico ambiental é coletivo e, não pode ser ofendido como um bem jurídico individual" (NASCIMENTO, 2013, p.516). Isto porque, quando há degradação ambiental, os seus reflexos e consequências são sentidos em toda a parte do mundo, não podendo definir qual local fora afetado, além de afetar as gerações atuais e futuras, por isso o meio ambiente é entendido como um bem e direito difuso.

Ferrer propõe uma busca de mecanismo para assegurar a materialização da solidariedade "no mesmo diapasão de inspiração de novos direitos transnacionais, como é caso do direito ambiental" (FERRER, 2002, p.21).

A solidariedade, quando se trata da transnacionalidade, é de suma importância, em que pese ela se referir na colaboração e cooperação entre os Estados, instituições e sociedade em geral (GREGÓRIO, 2017).

Destarte, "a colaboração e a solidariedade transnacionais também são as palavras de ordem para uma sustentabilidade global" (CRUZ; BODNAR, 2012, p.119), em que pese o Direito necessitar, portanto, de uma readequação das suas estratégias, por não dar mais respostas suficientes que assegurem um "futuro com mais sustentabilidade para toda a comunidade de vida e em escala global" (CRUZ; BODNAR, 2012, p.119).

A eficaz redução dos riscos e da vulnerabilidade aos desastres só será possível quando houve essa cooperação entre a sociedade civil global, conforme já dizia Bosselman, pois "elas representam toda a rede de relações internacionais e organizações que subjazem as sociedades para fora da esfera das instituições politicamente estabelecidas" (BOSSELMANN, 2015, p.256).

Muito mais que uma mera cooperação, faz-se necessário uma divisão de papéis e responsabilidade, função essencial da boa governança, "assim como a avaliação contínua das formas como os projetos e mecanismos de redução dos riscos de catástrofes têm impacto nos direitos humanos" (GREGÓRIO, 2017, p.403).

Assim, a responsabilidade, mais precisamente a ambiental empresarial, tem papel 
fundamental quando se trata em prevenção e precaução de danos ambientais, pois, pode-se dizer que a empresa e o Estado são socialmente sustentáveis quando, além de respeitar leis e regras das mais diversas áreas, espera que sua atitude seja positiva para a construção de uma sociedade justa e sustentável.

Nesse sentido, a construção de um espaço público transnacional se relaciona com a questão ambiental que poderia ocupar um papel também na construção do Direito Transnacional, que se destina a "garantir os mínimos de segurança típica do Estado Constitucional Moderno" (CRUZ; BODNAR, 2012, p. 07), superada pela questão ambiental como paradigma do ordenamento jurídico transnacional.

Cruz (2012) explana sobre a questão da cooperação da sociedade civil global, que o futuro da humanidade e do capitalismo é a junção da Democracia, sustentabilidade, lucro e interesse social transnacional para o bem o comum.

Os Indicadores Ethos de Responsabilidade Social Empresarial (IERSE) geram relatórios de sustentabilidade, com o desempenho organizacional para o desenvolvimento sustentável. Surgido no Brasil, o Instituto Ethos se espalhou pelo mundo, organizando, inclusive, com parcerias de outros institutos, os Indicadores Ethos na América Latina.

Os indicadores são organizados em sete temas: valores, transparência e governança, público interno, consumidores e clientes, comunidade, governo, sociedade e meio ambiente:

\footnotetext{
Sua premissa básica consiste numa prática usual e diária de ações de Responsabilidade Social no ambiente interno das corporações, conscientes de que o seu papel na sociedade inclui o exercício do envolvimento nas dimensões: econômica, legal, ética, política e filantrópica. A observação de todos os indicadores avaliados demonstra uma sintonia entre eles quanto a alguns temas comuns, como responsabilidade interna, responsabilidade externa e relacionamento com os stakeholders (GOMES, 2010, p.248).
}

Tais indicadores, portanto, demonstram a influência da Responsabilidade Ambiental sobre o valor da marca da empresa, reputação e satisfação dos stakeholders e o risco de externalidades negativas, isto tudo em âmbito global.

Assim, fica evidente que se faz necessária a implantação de novas estratégias de governança transnacional, atreladas a uma Responsabilidade Ambiental Empresarial, que sejam capazes de desenvolver atitudes solidárias e cooperativas na luta pela proteção do meio ambiente, de forma que seja assegurado para as futuras gerações.

Portanto, o desenvolvimento sustentável em termos globais, é totalmente dependente da participação de toda a sociedade e de todos os países para que sejas possíveis uma proteção ambiental eficaz e uma vida digna. 


\section{CONSIDERAÇÕES FINAIS}

Ao final do presente estudo, o qual analisou a Teoria da Responsabilidade Ambiental Empresarial e da Transnacionalidade, bem como do Direito Transnacional, tendo em vista que a atual sociedade, que se encontra inserida e envolta pelo fenômeno da globalização, necessita desenvolver novas estratégias para que suas necessidades sejam alcançadas diante das diversas mudanças globais.

Procurou-se, então, estudar a Responsabilidade Ambiental Empresarial, apresentando algumas de suas principais características e sua relação com a sociedade a qual a empresa está inserida, pois, verificou-se que, ser socialmente responsável vai muito além do que seguir leis e regras, necessitando da implementação de ações empresariais eficientes, que se preocupem, também, com as necessidades da sociedade e do meio ambiente global.

Responsabilidade Ambiental Empresarial, então, abrange os conceitos de cidadania corporativa, desenvolvimento sustentável, crescimento sustentável, sustentabilidade, filantropia empresarial, ética empresarial e ativismo social empresarial.

Quanto à Transnacionalidade, foram apresentadas algumas de suas manifestações, demonstrando que no contexto globalizado atual, o conceito de internacional não consegue atender à todas as demandas, necessitando de algo mais amplo, surgindo, então, a sua utilização.

Tal expressão engloba todas as ações e atitudes que transcendem as fronteiras, por isso é que se menciona atualmente, notadamente quanto à temática ambiental, as fronteiras físicas estatais não possuem qualquer relevância.

Surge assim, uma cooperação necessária e imprescindível entre os Estados, pois é perceptível que as ações e decisões que são tomadas por um Estado, são sentidas por todos os outros.

Já dizia Ulrich Beck, "pensar globalmente, agir localmente", o que se relaciona diretamente com a Transnacionalidade.

Analisando do ponto de vista ambiental, percebe-se a relação da Responsabilidade Ambiental Empresarial com a Transnacionalidade, pois, cada vez mais são vistos desastres naturais causados pelos homens que atingem a toda uma população, sendo que parte dela não está inserida no local do desastre.

O estudo da dimensão transnacional da Responsabilidade Ambiental Empresarial é de extrema relevância pois demonstra que assim como os danos são sentidos por todos, também as suas ações para prevenção e precaução o são.

A empresa ou Estado que age responsavelmente em suas ações com o meio ambiente da sua região, concebe um bem maior para toda a coletividade global.

Há, então, a necessidade de conscientização da humanidade para com o 
desenvolvimento sustentável em termos globais, dependendo da participação de toda a sociedade civil global. Somente assim se atingirá uma eficaz proteção ambiental, em prol dos direitos humanos e do meio ambiente global.

\section{REFERÊNCIAS}

ABNT. Gestão de riscos: Princípios e diretrizes. ISSO 26000:2010.

BOSSELMANN, Klauss. O princípio da Sustentabilidade: Transformando Direito e Governança. Revista dos Tribunais; São Paulo, 2015.

CRUZ, Paulo Marcio. BODNAR, Zenildo. Globalização, transnacionalidade e sustentabilidade. Itajaí: Univali, 2012.

CRUZ, Paulo Márcio; BODNAR, Zildo. A transnacionalidade e a emergência do Estado e do Direito transnacionais. Revista eletrônica do CEJUR, 2009.

CRUZ, Paulo Márcio; FERRER, G. R. Soberanía y transnacionalidad: antagonismos y consecuencias. Barcelona: Revista de Derecho. vLex, v. 63, 2008.

DIAS, Reinaldo. Gestão ambiental: responsabilidade social e sustentabilidade. 1.ed. São Paulo: Atlas, 2007.

FERRER, Gabriel Real. La construcción del Derecho Ambiental. Revista de Derecho Ambiental. Pamplona/ES, n.1, p.73-93, 2002. Disponível em:

http://www.dda.ua.ess/documentos/construccion_derecho_ambiental.pdf. Acesso em: 10 dez.2018.

GOMES, Giovanni de Araújo. Et al. Responsabilidade Socioambietnal Corporativa e Indicador de Maturidade medindo desempenho estratégico para as organizações. Revista de Ciências da Administração. v. 12, n. 26, p. 244-269, jan/abril 2010.

GREGÓRIO, Carolina Lückemeyer. Considerações acerca das responsabilidades e obrigações entre Estados perante a Transnacionalidade de desastres ambientais. v. 6. n.02, p. 385-412. BJIR: Marília, maio/ago. 2017

JESSUP, Philip C. Direito Transnacional. Editora Fundo de Cultura, 1965.

$\mathrm{KOH}$, Harold Hongju. Por que o direito transnacional é importante. Facult Scholarship Series. Paper 1793. 2006.

LACERDA, Adriana dos Santos. MOURA, Denise. A Responsabilidade Socioabiental como estratégia de competitividade para as organizações da contemporaneidade. Congresso Nacional de Excelência em Gestão. ISSN 1984-9354. 2016.

MASCARENHAS, Maria Paula Vilhena. COSTA, Cristiana dos A. Fernandes. Responsabilidade Social e Ambiental das Empresas: uma perspectiva sociológica. Latitude, vol. 7, n², pp.141- 
167, 2011.

NASCIMENTO, Eliana Maria de Senna. CARPENA, Gislane. Transnacionalidade e a responsabilidade civil ambiental: proteção ambiental como um direito humano transfronteiriço. Justiça do Direito. v. 27, n. 2, jul./dez. 2013 - p. 506-525.

PALHARES, José Mauro. NAGATA, Nilson. Responsabilidade Social e Ambiental das Empresas: um Estudo das Ações Praticadas pela Itaipu Binacional. Universidade de Coimbra. 2010.

PASOLD, Cesar Luiz. Metodologia da pesquisa jurídica: teoria e prática.13 ed. Florianópolis: Conceito Editorial, 2015.

PIFFER, Carla; CRUZ, Paulo Márcio. MIGRAÇÕES TRANSNACIONAIS. In: Francisco José Rodrigues de Oliveira Neto; Pedro Manoel Abreu; Orlando Luiz Zanon Junior. (Org.). Direito, Democracia e Constitucionalismo. 1ed. Itajaí-SC: UNIVALI, 2017, v. 1, p. 121-137.

PIFFER, Carla; CRUZ, Paulo Márcio; BALDAN, Guilherme Ribeiro. Transnacionalidade e sustentabilidade: dificuldades e possibilidades em um mundo em transformação. 1. ed. Porto Velho: EMERON, 2018. v. 1.

RIBEIRO, Gustavo Lins. A condição da Transnacionalidade. Série Antropologia, Brasília, v.223, 1197. 